\title{
Photoperiodic induction of diapause in the spider mite Tetranychus urticae: qualitative or quantitative time measurement?
}

\author{
ANNEMARIE KROON, RENÉ L. VEENENDAAL and \\ ALFRED VEERMAN \\ Institute for Systematics and Population Biology, University of Amsterdam, The Netherlands
}

\begin{abstract}
Insects and mites may measure photoperiods either by classifying them as long or short relative to a critical value (qualitative time measurement) or by using the absolute value (quantitative time measurement). The spider mite Tetranychus urticae is thought to use a qualitative mechanism of time measurement. In this paper we present the results of experiments with an inbred line of the spider mite (to keep genetic variation in photoperiodic responses small), to test whether quantitative aspects also play a role. Differences in diapause incidence in different long-night photoperiods at different temperatures may be an indication of quantitative responses to photoperiod.

The effect of temperature on the photoperiodic response curve was studied at $16^{\circ} \mathrm{C}$, $19^{\circ} \mathrm{C}$ and $22^{\circ} \mathrm{C}$. The response curves appeared to be similar at $16^{\circ} \mathrm{C}$ and $19^{\circ} \mathrm{C}$, with a critical nightlength between 10 and $11 \mathrm{~h}$. At $22^{\circ} \mathrm{C}$, diapause induction was less than $100 \%$ in all long-night regimens and the critical nightlength had shifted to $12 \mathrm{~h}$. Maximum diapause induction (93\%) occurred in a light-dark cycle with a $16 \mathrm{~h}$ dark phase (LD 8:16 h). Diapause induction was lowest in long-night photoperiods with dark phases of $20 \mathrm{~h}$ and longer.

The number of light-dark cycles needed for $50 \%$ diapause induction at $19^{\circ} \mathrm{C}$ varied between 12.1 and 14.7 for LD 6:18 h, between 10.9 and 12.5 for LD 8:16 h, between 10.6 and 11.6 for LD 10:14 h, and between 10.1 and 10.7 for LD 12:12 h. Independent of the light-dark regimen, diapause induction took place in some individuals after receiving 8 cycles and virtually all individuals entered diapause after 16 cycles.

No effect was found of the photoperiodic treatment during prediapause development (LD 6:18 h, LD 8:16 h, LD 10:14 h, LD 12:12 h) on diapause duration. The average diapause duration at $\mathrm{LD} 10: 14 \mathrm{~h}$ and $19^{\circ} \mathrm{C}$ was 61 days over all four treatments.

We explained the results by hypothesising that nightlengths are assessed qualitatively and that the photoperiodic clock operates more accurately near the critical nightlength.
\end{abstract}

Key words. Photoperiodism, diapause, quantitative time measurement, spider mites, Tetranychus urticae, Acari, Tetranychidae.

\section{Introduction}

Diapause is an adaptive strategy of many insects and mites in that it synchronizes their life cycle with the availability of food and it enables them to avoid unfavourable physical conditions such as cold, heat or drought. Diapause occurs either as an

Correspondence: A. Kroon, University of Amsterdam, Institute for Systematics and Population Biology, Section Population Biology, Kruislaan 320, 1098 SM Amsterdam, The Netherlands. obligatory phase of individual development or in response to cue factors. In the temperate regions photoperiod is the major cue controlling diapause induction and maintenance (Tauber et al., 1986; Danks, 1987). Therefore, a photoperiodic clock measuring the length of light and/or dark phases of photoperiodic cycles is of vital importance for both insects and mites. It has been shown that, in most species, measurement of nightlength is more important than measurement of daylength to bring about a photoperiodic response (Saunders, 1982).

Over the past decades, the study of photoperiodic responses (diapause, morph determination) in terrestrial arthropods has 
resulted in several theoretical models for photoperiodic time measurement. Prominent examples are: the 'external coincidence model' (Pittendrigh \& Minis, 1964; Pittendrigh, 1966; Saunders, 1982), the 'internal coincidence model' (Tyshchenko, 1966; Pittendrigh, 1972), the 'nonoscillatory hourglass timer model' (Lees, 1966, 1973), and the 'hourglass timer-oscillator counter model' (Vaz Nunes \& Veerman, 1982). Notwithstanding substantial differences, these clock models share one characteristic concerning photoperiod perception. The duration of the night is 'simply' compared with some critical value and classified as either long or short relative to this threshold, i.e. time is measured in a relative or qualitative manner. In diapause research the threshold value is the "critical nightlength', which is by definition the nightlength at which $50 \%$ of a population enters diapause.

As an alternative, quantitative measurement of the nightlength has been hypothesized. Here the clock perceives the absolute length of nights. Several papers on diapause in arthropods show that the photoperiodic clock appears to measure the absolute nightlength rather than classifying photoperiods as belonging to either the long-night or the shortnight type (Zaslavski, 1972, 1988; Tauber \& Tauber, 1973; Hardie, 1990; Kimura, 1990; Spieth \& Sauer, 1991). Recent models of the photoperiodic clock include quantitative time measurement, e.g. the 'damped oscillator model' (Saunders \& Lewis, 1988), the 'commanding link model' (Zaslavski, 1988), and the 'coupled oscillator feedback system' (Vaz Nunes et al., 1991a,b).

Quantitative responses to photoperiods (i.e. different longnight or different short-night photoperiods affect diapause characteristics differently) lend support to the notion of quantitative or absolute time measurement. For the study of the photoperiodic clock, animals are generally exposed to light-dark regimens and the eventual response, diapause or nondiapause, is determined ('black box' experiments). Thus, the net results of these type of experiments, the photoperiodic responses, are used to gain insight into the operation of the clock. For most species investigated it has been concluded that measurement of time is based on a qualitative principle. However, these inferences were made from experiments with designs inappropriate to discriminate between a qualitative and quantitative principle. To detect quantitative responses, special experimental schemes are needed as explained below.

One method would be to study the impact of absolute nightlength of the induction regimen on diapause incidence. 'Strong' long nights would induce higher percentages of diapause than 'weak' long nights. Another method to discover quantitative responses to photoperiod is to study the effect of the absolute nightlength of the induction regimen on diapause intensity or diapause duration. It is well known for many species that environmental factors such as daylength, temperature or moisture experienced after the induction of diapause, may have an influence on diapause intensity (Tauber et al., 1986). Some authors studied the effect of prediapause environmental conditions on the subsequent rate of diapause development (Bell \& Adkisson, 1964; Kimura, 1983, 1990; Numata \& Hikada, 1983; Numata, 1985; Beck, 1989).

In this paper, photoperiodic time measurement in the two- spotted spider mite Tetranychus urticae is studied. Diapause in the spider mite is induced by long-night photoperiods experienced during preimaginal development and is expressed in the adult stage in females only. Mites which have entered diapause cannot leave this state instantaneously in response to favourable conditions. Activity can only be resumed after completion of a physiological process, called 'diapause development' (Veerman, 1985). According to Tauber et al. (1986), diapause development ends when photoperiodic control of diapause maintenance is lost. In T. urticae diapause development is accelerated and rapidly completed when short nights are experienced, but persists for several weeks to two or three months (depending on the strain) when mites are kept under long nights. Thus, diapause development in this mite proceeds gradually under a long-night photoperiod (Veerman, 1985; Koveos et al., 1993a,b; Koveos \& Veerman, 1994).

Here, diapause inductive strengths of different long-night photoperiods are measured. Three experiments have been carried out, each taking a different approach to solve the question, whether photoperiodic time measurement in the spider mite is based on a qualitative or quantitative principle. In the first experiment temperature is varied. Differences in diapause incidence in different long-night photoperiods and at different temperatures would be an indication of differences in diapause inductive strength. In the second experiment, both nightlength and the number of light-dark cycles are varied. The relationship between number of light-dark cycles and diapause incidence can reveal differences in diapause inductive strength of photoperiods. In the third experiment, the influence of the photoperiod of the induction regimen on diapause intensity is investigated.

\section{Materials and Methods}

A Dutch strain of T. urticae, called 'Voorne', has been reared in the laboratory on bean plants (Phaseolus vulgaris) since 1961. For this study, an inbred line of the Voorne strain, obtained by sib-mating for 20 generations, was used to keep genetic variation in photoperiodic response small. Reduction in genetic variation was achieved by starting each of the 20 generations with one female inseminated by a brother. Stock mites were kept at $22^{\circ} \mathrm{C}$ under long-day illumination $(17 \mathrm{~h}$ of light and $7 \mathrm{~h}$ of darkness, or LD 17:7 h).

The spider mite $T$. urticae exhibits a facultative reproductive diapause which is expressed in females only; males do not survive the winter period. The most important characteristics of diapausing females are the orange colouration, in contrast to the greenish summer form, and the absence of egg-laying (Veerman, 1985).

For the experiments, female mites were allowed to lay eggs for $24 \mathrm{~h}$ on detached bean leaves (twenty-five mites/leaf), in continuous illumination and at $26^{\circ} \mathrm{C}$. At this temperature egg production is high and hatching occurs rapidly after another three days of incubation.

Experiments were carried out in temperature- and photoperiod-controlled incubators, in which light intensity at 
the level of the mites was $\top 1000$ lux and temperature was maintained constant within $\pm 0.5^{\circ} \mathrm{C}$.

The colour of females was used to determine the diapause state. A female was considered to be in diapause when she had changed to the orange colour, or in nondiapause when she remained green.

\section{Effect of temperature on the photoperiodic response}

Leaves with eggs near hatching were transferred to various photoperiodic regimens at $16^{\circ} \mathrm{C}, 19^{\circ} \mathrm{C}$ or $22^{\circ} \mathrm{C}$, at which the mites completed their entire postembryonic development (below $16^{\circ} \mathrm{C}$ mites develop very slowly and above $24^{\circ} \mathrm{C}$ no diapause can be induced; Helle, 1962). The number of females used in each test regimen was about 200. Percentages of diapause induction were determined 6 weeks $\left(16^{\circ} \mathrm{C}\right)$, 4 weeks $\left(19^{\circ} \mathrm{C}\right)$ or 3 weeks $\left(22^{\circ} \mathrm{C}\right)$ after the start of the experiment, when all mites had developed into adults and had either changed colour or had started to lay eggs.

Effect of the number of photoperiodic cycles on diapause incidence in four light-dark regimens

After the incubation period of 4 days at $26^{\circ} \mathrm{C}$, leaves with eggs near hatching were transferred to one of four photoperiodic regimens at $19^{\circ} \mathrm{C}(\mathrm{LD} \mathrm{6:18} \mathrm{h}, \mathrm{LD} 8: 16 \mathrm{~h}, \mathrm{LD} \mathrm{10:14} \mathrm{h}$ or LD 12:12 h). Exposure of mites to one of these inductive lightdark regimens varied from one up to 18 cycles. Thereafter, mites completed their development at continuous light (LL) and $19^{\circ} \mathrm{C}$. In the spider mite T. urticae, continuous light is considered to be 'neutral'; it does not induce diapause nor does it counteract the effect of previously experienced long nights (Veerman, 1977). Four weeks after the beginning of the experiment, the percentages of diapause incidence were determined. Experiments in which mites were exposed to between 8 and 16 light-dark cycles were repeated several times (LD 6:18 h, 4 repeats; LD 8:16 h, 4 repeats; LD 10:14 h, 3 repeats; LD 12:12 h, 2 repeats). The number of females used in each test regimen was about 200 .

The diapause induction curves were compared using a method based on the generalized likelihood ratio test (Sokal \& Rohlf, 1981; Haanstra et al., 1985). Curves were fitted to the following model (sigmoidal curve), for which the SYSTAT package was used. Three parameters (c, b, and a) were estimated for each curve by the least squares method.

$Y=\mathrm{c} /\left[1+\exp \left(\mathrm{b}^{*}(X-\mathrm{a})\right)\right]+\mathrm{E}$

$Y=(100-$ percentage diapause induction $)$

$X=$ natural $\log$ of the number of light-dark cycles experienced

$\mathrm{E}=$ stochastic error term

$\mathrm{c}=$ maximum diapause induction

$\mathrm{b}=$ slope parameter

$\mathrm{a}=$ natural $\log$ of the number of cycles needed for $50 \%$ diapause induction.

A Chi-squared test ( $\alpha=0.05$ ) was used to determine whether differences between curves were significant (Sokal \& Rohlf, 1981).

\section{Effect of photoperiod of the induction regimen on diapause intensity}

Leaves with eggs near hatching were transferred to one of four inductive regimens at $19^{\circ} \mathrm{C}(\mathrm{LD} 6: 18 \mathrm{~h}, \mathrm{LD} 8: 16 \mathrm{~h}, \mathrm{LD}$ $10: 14 \mathrm{~h}$ or LD $12: 12 \mathrm{~h}$ ) to complete their postembryonic development in about three and a half weeks. Diapausing females were then stored for three weeks at $4{ }^{\circ} \mathrm{C}$, whereupon females of all four treatments were transferred to LD 10:14 h and $19^{\circ} \mathrm{C}$ and put onto bean leaf discs (one female per leaf disc; about 200 females per treatment). Diapause duration was measured for each female individually (diapause duration is a measure for diapause intensity, cf. Koveos et al., 1993a). The period of cold storage was not included in the duration of diapause as presented in Fig. 3.

In previous diapause termination experiments, responses of populations were investigated and the criterion for diapause termination was the change from the orange winter colour of the females to the greenish summer colour (Koveos et al., 1993a,b; Koveos \& Veerman, 1994). This method has disadvantages when diapause duration is being measured. First, the moment of colour change is often not easy to determine, because of intermediate colour forms. Secondly, statistical analysis of the results is difficult. In this experiment the appearance of the first $\operatorname{egg}(\mathrm{s})$ was taken as the criterion for diapause termination. A short period of postdiapause development is therefore included in the diapause duration as presented in Fig. 3. All females were observed every other day and, when necessary, deteriorated leaf discs were replaced by fresh ones.

The means of the samples with confidence limits (95\%) were determined for the four groups (Sokal \& Rohlf, 1981). The results were subjected to a one-way analysis of variance (ANOVA). This method was used to test the effect of one factor (photoperiod) on diapause duration ( $H_{o}$-hypothesis: photoperiod has no effect on diapause duration). For application of an ANOVA the underlying assumptions, normal distribution and homogeneity of the variances, have to be valid.

\section{Results}

Effect of temperature on the photoperiodic response

Figure 1 shows the photoperiodic response curves for diapause induction at three different temperatures. The critical nightlength appeared to be between 10 and $11 \mathrm{~h}$, when diapause was induced at $16^{\circ} \mathrm{C}$ or $19^{\circ} \mathrm{C}$. Long-night photoperiods with dark phases from 11 to $23 \mathrm{~h}$ resulted in $88-100 \%$ diapause, whereas short-night photoperiods with dark phases of $9 \mathrm{~h}$ and shorter completely prevented diapause. At $22^{\circ} \mathrm{C}$ the critical nightlength had shifted to $12 \mathrm{~h}$ and the percentage diapause induction was less in all long-night regimens compared to the percentage diapause induction at $16^{\circ} \mathrm{C}$ and $19^{\circ} \mathrm{C}$. This reduction 


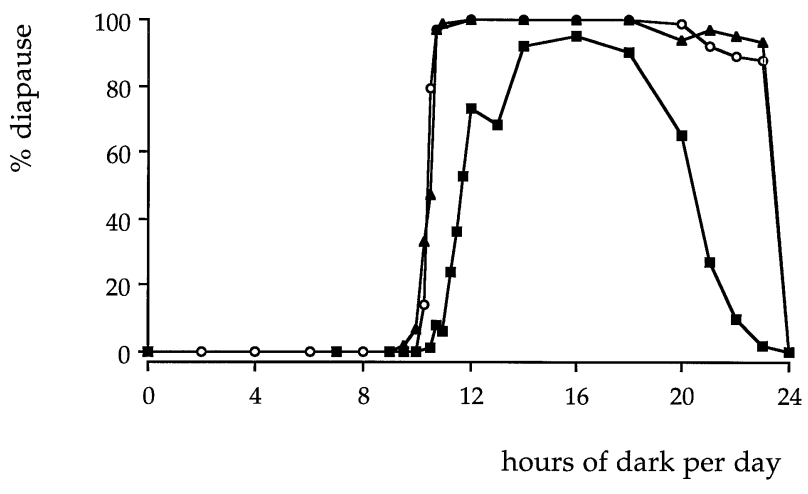

Fig. 1. Photoperiodic response curves for diapause induction determined at $16^{\circ} \mathrm{C}(\bigcirc) 19^{\circ} \mathrm{C}(\boldsymbol{\Delta})$ and $22^{\circ} \mathrm{C}(\boldsymbol{\square})$.

in percentage diapause was not the same for all long-night photoperiods. 'Intermediate' long nights with dark phases of $14-18 \mathrm{~h}$ still resulted in $90-93 \%$ diapause, whereas in photoperiods with extremely long nights, diapause induction had decreased to $65 \%$ in LD 4:20 h down to $2 \%$ in LD 1:23 h (Fig. 1). Furthermore, the transition from no diapause induction at all (at short nights) to a high percentage of diapause induction was less steep at $22^{\circ} \mathrm{C}$ than at $16^{\circ} \mathrm{C}$ and $19^{\circ} \mathrm{C}$.

The diapause inductive strength of a photoperiod is measured from the percentage diapause induced; a 'strong' long night induces a higher percentage diapause than a 'weak' long night. From our results we conclude that differences in diapause inductive strength between photoperiods, which were barely noticeable at $16^{\circ} \mathrm{C}$ and $19^{\circ} \mathrm{C}$, were apparent at $22^{\circ} \mathrm{C}$.

Effect of the number of photoperiodic cycles on diapause incidence in four light-dark regimens

The results of the experiments in which we studied the effect of the number of photoperiodic cycles on diapause incidence at four light-dark regimens are presented in Fig. 2. The shapes of the curves are generally similar. Diapause induction appeared to require at least 8 long-night cycles and the photoperiodic response reached saturation after about 16 cycles. In most cases, the slope parameter (b) did not differ significantly between curves.

The number of cycles needed for $50 \%$ diapause induction differed significantly within treatments $\left(\chi^{2}=83.5\right.$ for LD 6:18 h, $\chi^{2}=68.0$ for LD 8:16 h, $\chi^{2}=68.1$ for LD 10:14 h and $\chi^{2}=12.2$ for LD 12:12 h). Therefore, the results of repeats of the experiment could not be averaged.

There is a tendency that, the more removed from the critical light-dark cycle (LD 13.5:10.5 h), the more cycles were needed for induction of $50 \%$ diapause. This number of cycles varied between $12.1( \pm 0.1)$ and $14.7( \pm 0.4)$ for LD 6:18 h, between $10.9( \pm 0.3)$ and $12.5( \pm 0.2)$ for LD $8: 16 \mathrm{~h}$, between $10.6( \pm 0.1)$ and $11.6( \pm 0.3)$ for LD 10:14 h, and between $10.1( \pm 0.2)$ and $10.7( \pm 0.3)$ for LD 12:12 h (95\% confidence intervals between parentheses). For analysis of the effect of photoperiod on diapause incidence, only simultaneously determined curves were compared. The four curves of the
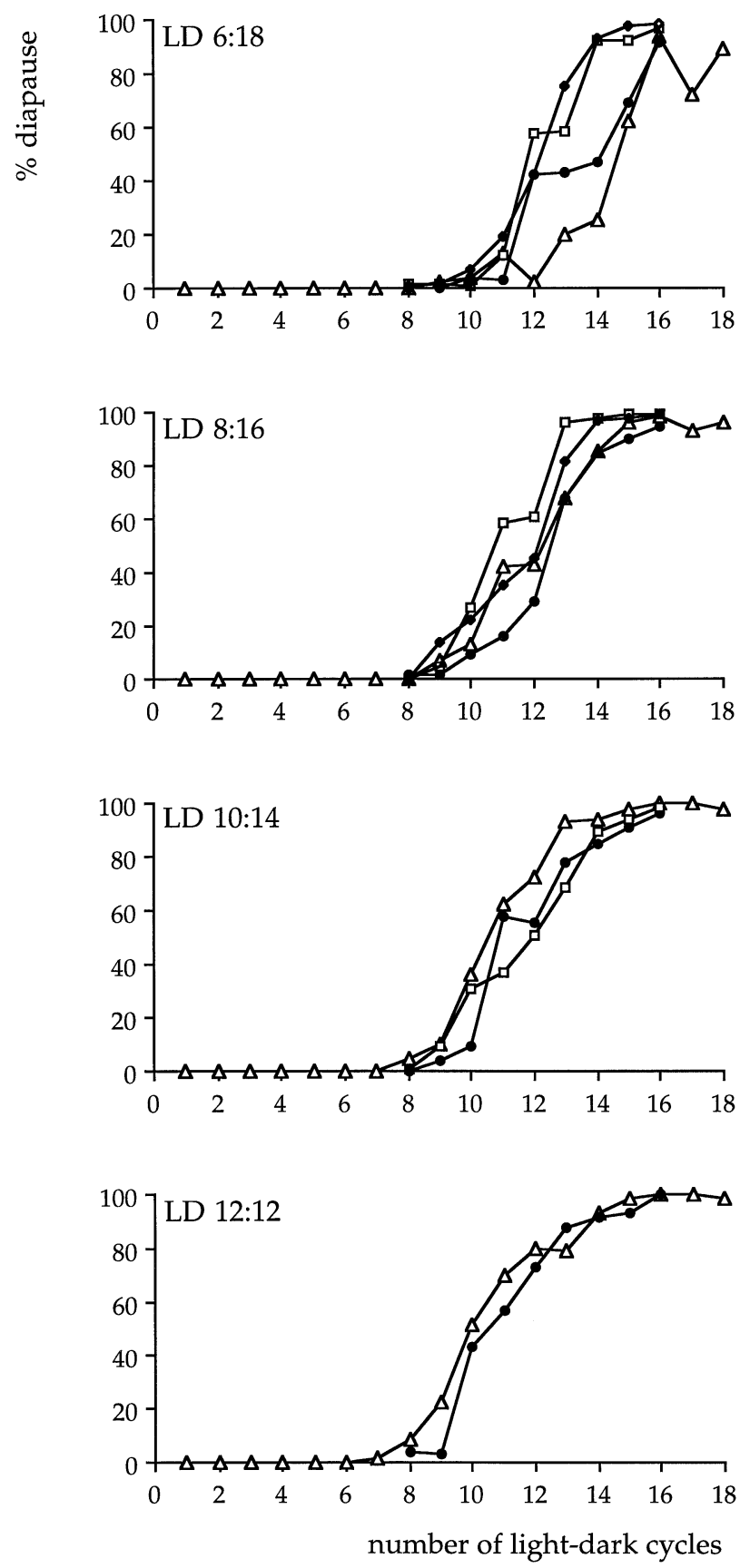

Fig. 2. Diapause incidence at $19^{\circ} \mathrm{C}$ in response to a varying number of cycles of the photoperiods: LD 6:18 h, LD 8:16 h, LD 10:14 h and LD $12: 12 \mathrm{~h}, \triangle$ first repeat of the experiment; $\boldsymbol{\bullet}$, second repeat; $\square$, third repeat; $\diamond$, fourth repeat.

first repeat of the experiment (Fig. 2, open triangles) had significantly different a-parameters $\left(\chi^{2}=16.7\right)$; the four lightdark treatments differed in number of cycles needed for $50 \%$ diapause induction. Also, the analysis of the second series of experiments (black circles) demonstrated a significant difference in the a-parameter $\left(\chi^{2}=89.2\right)$. In the two series of experiments discussed above it was shown that the more 

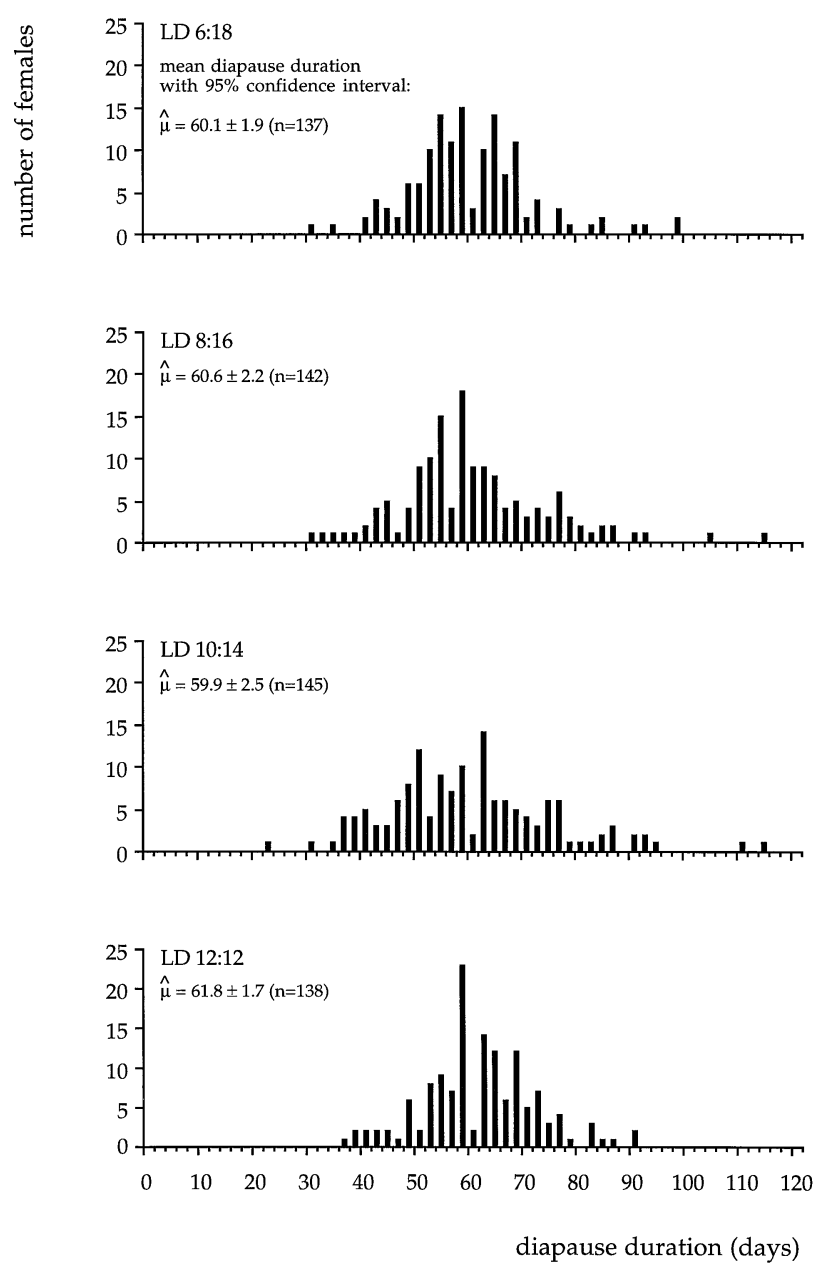

Fig. 3. Duration of diapause (with means and $95 \%$ confidence intervals) at $\mathrm{LD} 10: 14 \mathrm{~h}, 19^{\circ} \mathrm{C}$. Diapause was induced at four different light-dark regimens (LD 6:18 h, LD 8:16 h, LD 10:14 h and LD 12:12 h). Diapause females were kept for three weeks at $4^{\circ} \mathrm{C}$ before transfer to the reactivation regimen (LD 10:14 h). Period of cold storage was not included in diapause duration.

removed from the critical light-dark cycle, the more cycles were needed for induction of $50 \%$ diapause. But in the third repeat of the experiment, which was carried out for three photoperiods (open squares), the lowest number of cycles needed for $50 \%$ diapause induction was found at LD 8:16 h $(10.9 \pm 0.3)$; it differed significantly from that found at the other two light-dark treatments $\left(\chi^{2}=71.1\right)$.

\section{Effect of photoperiod of the induction regimen on diapause intensity}

The results of the experiment in which the impact of nightlength of the induction regimen on diapause duration was studied, are presented in Fig. 3. The average duration of diapause (in which the period of cold storage was not included) was about 61 days for all four treatments, ranging from $59.9( \pm 2.5)$ days for $\operatorname{LD} 10: 14 \mathrm{~h}$ to $61.8( \pm 1.7)$ days for
LD 12:12 h (95\% confidence intervals in parentheses). The data sets of the four treatments did not depart from a normal distribution (Kolmogorov-Smirnov: $P<0.0001$ for all four groups), and variances were homogeneous (Bartlett's test: $\chi^{2}=$ $11.35 ; P<0.01)$. There was no significant effect of the lightdark treatments on diapause duration $\left(F_{(3,558)}=0.63 ; P>0.5\right)$. During the first half of the experiment, there seemed to be some slight difference in diapause completion rate between the LD 12:12 $\mathrm{h}$ group and the other three groups. The median reactivation time at LD 12:12 h was 62 days, while it was 58, 59, and 58 days at LD 6:18 h, LD 8:16 h and LD 10:14 h, respectively. However, this difference between treatments subsequently disappeared.

Photoperiod of the induction regimen did not influence survival of the mites during diapause development (survival varied between $69 \%$ and $73 \%$ ).

\section{Discussion}

Effect of temperature on the photoperiodic response

Differences in diapause inductive strength between longnight photoperiods were hardly noticeable at lower temperatures in $T$. urticae, but were significant at a higher temperature. Differences could be masked at lower temperatures, because there may exist 'supersaturated' responses in the underlying physiological mechanism. Lewis \& Saunders (1987) assume in their model that during the exposure to long-night photoperiods a hypothetical diapause-inducing substance is accumulated. The 'induction sum', which directly depends on the concentration of this substance, can exceed that which is needed for diapause induction and they hypothesize, therefore, that photoperiodic responses could be 'supersaturated'. However, the idea that photoperiods can induce 'supersaturated' responses in a population is not testable with the kind of experiments used here. In our experiment, photoperiods with 'intermediate' long nights have a higher diapause inductive strength than photoperiods with extreme long nights and than photoperiods near the critical nightlength. Helle (1962) did find in the original 'Voorne' strain of T. urticae a small difference in diapause inductive strength between extreme long nights and intermediate long nights also at a lower temperature. Differences in diapause inductive strength between long-night photoperiods were also found in the bean bug, Riptortus clavatus (Numata, 1985), in the fruitfly, Drosophila testacea, and in the D. auraria species-complex (Kimura, 1982, 1983, 1990).

Differences in diapause inductive strength between photoperiods are generally thought to support the notion of quantitative time measurement; if different long nights bring about differences in incidence of diapause the clock has to be able to discriminate between them (cf. Zaslavski, 1988). We argue that the results of our experiment with spider mites can be explained with a variant of the qualitative time measurement model. In this qualitative model it is assumed that the critical nightlength is not a fixed value in an individual but can itself be influenced by temperature (Tauber et al., 1986; Danks, 
1987), and that photoperiodic time is measured more accurately near the critical nightlength; time measurement involves a comparison of a nightlength with some critical value.

The reduction in percentage diapause found near the critical nightlength at the highest temperature may be explained by a temperature-dependent threshold value. At higher temperatures the critical nightlength has shifted towards photoperiods with longer nightlengths; actual nightlengths are just compared to another value to classify them as either long or short. The reduction of percentage diapause induction at extreme long nights could be explained by the second assumption of the model, that time measurement is more accurate near the critical nightlength. This assumption is not unreasonable, because assessing photoperiods near the critical photoperiod is crucial for entering diapause at the end of summer. It is of less importance to measure extremely long nights accurately in nature, because they occur when animals are in diapause already for weeks or months. It is quite possible that at lightdark regimens with unnaturally long nights, other external variables than photoperiod, such as temperature, food quality, humidity or internal physiological factors, play a more important role in the decision on diapause or nondiapause. As a speculative explanation for assuming inaccuracy at extremely long nights we suggest that the minimum period of light that the clock needs to reset itself for the next act of time measurement (Vaz Nunes \& Veerman, 1986) is not the same for all individuals of the population. For part of it a light period of $6 \mathrm{~h}$ is close to the limit or just not long enough for resetting after every measurement, as a result of which the clock operates more 'sloppily'.

\section{Effect of the number of photoperiodic cycles on diapause incidence in four light-dark regimens}

The relationship between number of light-dark cycles required and diapause incidence can reveal differences in inductive strength of long nights: 'strong' long nights need fewer light-dark cycles for diapause induction than 'weak' long nights (cf. Zaslavski, 1988). Although, on the whole, the within-treatment differences were as large as the betweentreatment differences in number of light-dark cycles needed for $50 \%$ diapause induction, we conclude that the diapause inductive strength of a photoperiod with an extreme long night is lower than that of a photoperiod with a nightlength near the critical one. It is questionable, however, whether this small difference in inductive strength proves that photoperiodic time is measured quantitatively in the spider mite $T$. urticae. The tendency for an increase in the number of light-dark cycles for $50 \%$ diapause induction with nightlength of the induction regimen may also be explained by the fact that at extreme long nights other factors may influence the eventual response, diapause or nondiapause, as explained above. The withintreatment variation in responses of mites was the largest at the regimen with the longest nightlength (though we have to bear in mind that the number of repeats is small). We suspect that this is due to inaccuracies of time measurement at extreme photoperiods. The results can therefore be explained by the variant of the qualitative time measurement model discussed above.

\section{Effect of photoperiod of the induction regimen on diapause intensity}

In the last experiment, no effect of nightlength of the induction regimen on diapause intensity could be shown; average diapause duration was the same for all four groups. We conclude that diapause inductive strength of long-night photoperiods is not expressed in terms of differences in diapause intensity. These results lend additional support to the hypothesis that the photoperiodic clock in the spider mite T. urticae is based on a qualitative principle. The clock classified the photoperiods as long nights and diapause with some standard intensity followed. Differences in diapause intensity found within groups could be attributed to differences in individual traits and to (small) differences in food quality, temperature and/or humidity.

Our findings are not consistent with the results of a number of studies. Bell \& Adkisson (1964) found that sequences of LD 16:8 h-LD 12:12 h induced a more intense diapause than sequences of LD 14:10 h-LD 12:12 h in Pectinophora gossypiella. In the bean bug $R$. clavatus, diapause induced under LD 8:16 h or LD 10:14 h was more difficult to break than diapause induced under LD 12:12 h or LD 13:11 h (Numata \& Hidaka, 1983; Numata, 1985). In the fruitflies $D$. auraria, D. subauraria and D. triauraria, photoperiods with longer dark phases induce a more intense diapause than those with shorter dark phases (Kimura, 1983, 1990). Beck (1989) reported that intensity of diapause in the European corn borer, Ostrinia nubilalis, was controlled by temperature and by the absolute duration of the night of the rearing regimen. A $12 \mathrm{~h}$ scotophase evoked greater intensity of diapause than did either longer or shorter scotophases. Differences in diapause intensity found in the above mentioned studies represent evidence for differences in diapause inductive strength between photoperiods and, in this respect, could lend support to the hypothesis of quantitative time measurement.

Altogether our experimental results do not provide convincing evidence for quantitative time measurement. A quantitative response could be shown in only one out of three of our experiments; in the other two experiments quantitative effects were either small or not detectable. Therefore, we favour the most parsimonious hypothesis of qualitative time measurement. It is possible, however, that differences in 'diapause averting strength' between short nights are more distinct than differences in diapause inductive strength between long nights. Hardie (1990) observed in the aphid Megoura viciae no difference in inductive strength between long nights, but a great difference in inductive strength between short nights.

Other possible variants of the qualitative time measurement model are: a model in which the critical nightlength is fixed in an individual but variable within the population, and a model in which the critical nightlength in both an individual and within the population is variable. By using an inbred line for our experiments the possibility that quantitative effects found 
were caused by a large within-population variation in critical nightlength was excluded. Inaccuracy of measurement of the extreme photoperiods could be a marginal phenomenon of all possible models.

Our statement, that the photoperiodic clock in the spider mite T. urticae is based on a qualitative principle, is diametrically opposed to the opinion of Zaslavski (1988). He hypothesized that a photoperiod is always measured quantitatively, irrespective of whether the response elicited is qualitative or quantitative. Quantitative aspects may be masked during the cascade of events which take place between perception of photoperiod and the eventual photoperiodic response. What happens during these 'intervening events' is, however, still completely unknown for all arthropod species.

\section{Acknowledgements}

We cordially thank Matty Berg, Hans Breeuwer, Jan Bruin and Maurice Sabelis for comments on the manuscript, and Rob Lingeman and Els Smit for statistical advice.

\section{References}

Beck, S.D. (1989) Factors influencing the intensity of larval diapause in Ostrinia nubilalis. Journal of Insect Physiology, 35, 75-79.

Bell, R.A. \& Adkisson, P.L. (1964) Photoperiodic reversibility of diapause induction in an insect. Science, 144, 1149-1151.

Danks, H.V. (1987) Insect Dormancy: an Ecological Perspective. Biological Survey of Canada, Ottawa.

Haanstra, L., Doelman, P. \& Oude Voshaar, J.H. (1985) The use of sigmoidal dose response curves in soil ecotoxicological research. Plant and Soil, 84, 392-297.

Hardie, J. (1990) The photoperiodic counter, quantitative day-length effects and scotophase timing in the vetch aphid Megoura viciae. Journal of Insect Physiology, 36, 939-949.

Helle, W. (1962) Genetics of resistance to organophosphorus compounds and its relation to diapause in Tetranychus urticae Koch (Acari). Tijdschrift voor Plantenziekten, 68, 155-195.

Kimura, M.T. (1982) Effects of photoperiod and temperature on reproductive diapause in Drosophila testacea. Experientia, 38, 371-372.

Kimura, M.T. (1983) Geographic variation and genetic aspects of reproductive diapause in Drosophila triauraria and D. quadraria. Physiological Entomology, 8, 181-186.

Kimura, M.T. (1990) Quantitative response to photoperiod during reproductive diapause in the Drosophila auraria species-complex. Journal of Insect Physiology, 36, 147-152.

Koveos, D.S., Kroon, A. \& Veerman, A. (1993a) Geographic variation of diapause intensity in the spider mite Tetranychus urticae. Physiological Entomology, 18, 50-56.

Koveos, D.S., Kroon, A. \& Veerman, A. (1993b) The same photoperiodic clock may control induction and maintenance of diapause in the spider mite Tetranychus urticae. Journal of Biological Rhythms, 8, 265-282.

Koveos, D.S. \& Veerman, A. (1994) Accumulation of photoperiodic information during diapause development in the spider mite Tetranychus urticae. Journal of Insect Physiology, 40, 701-707.

Lees, A.D. (1966) Photoperiodic timing mechanisms in insects. Nature, 210, 986-989.
Lees, A.D. (1973) Photoperiodic time measurement in the aphid Megoura viciae. Journal of Insect Physiology, 19, 2279-2316.

Lewis, R.D. \& Saunders, D.S. (1987) A damped oscillator model of an insect photoperiodic clock. I. Description of the model based on a feedback control system. Journal of Theoretical Biology, 128, 47-59.

Lewis, R.D. \& Saunders, D.S. (1988) The photoperiodic clock and counter mechanism in two species of flies: evidence for damped circadian oscillators in time measurement. Journal of Comparative Physiology A, 163, 365-371.

Numata, H. (1985) Photoperiodic control of adult diapause in the bean bug, Riptortus clavatus. Memoirs of the Faculty of Science, Kyoto University, Series of Biology, X, 29-48.

Numata, H. \& Hikada, T. (1983) Photoperiodic control of adult diapause in the bean bug, Riptortus clavatus Thunberg (Heteroptera, Coreidae). II. Termination of diapause induced under different photoperiods. Applied Entomology and Zoology, 18, 439-441.

Pittendrigh, C.S. (1966) The circadian oscillation in Drosophila pseudoobscura pupae: a model for the photoperiodic clock. Zeitschrift für Pflanzenphysiologie, 54, 275-307.

Pittendrigh, C.S. (1972) Circadian surfaces and the diversity of possible roles of circadian organization in photoperiodic induction. Proceedings of the National Academy of Sciences of the United States of America, 69, 2734-2737.

Pittendrigh, C.S. \& Minis, D.H. (1964) The entrainment of circadian oscillations by light and their role as photoperiodic clocks. American Naturalist, 98, 261-294.

Saunders, D.S. (1982) Insect Clocks, 2nd edn. Pergamon Press, Oxford. Saunders, D.S. \& Lewis, R.D. (1988) The photoperiodic clock and counter mechanism in two species of flies: evidence for damped circadian oscillators in time measurement. Journal of Comparative Physiology A, 163, 365-371.

Sokal, R.R. \& Rohlf, F.J. (1981) Biometry, 2nd edn. Freeman and Co., New York.

Spieth, H.R. \& Sauer, K.P. (1991) Quantitative measurement of photoperiods and its significance for the induction of diapause in Pieris brassicae (Lepidoptera, Pieridae). Journal of Insect Physiology, 37, 231-238.

Tauber, M.J. \& Tauber, C.A. (1973) Quantitative response to daylength during diapause in insects. Nature, 244, 296-297.

Tauber, M.J., Tauber, C.A. \& Masaki, S. (1986) Seasonal Adaptations of Insects. Oxford University Press, New York.

Tyshchenko, V.P. (1966) A bioscillatory model of the physiological mechanism of insect photoperiodic reaction. Zhurnal Obshchei Biologii, 27, 209-222 (in Russian).

Vaz Nunes, M., Lewis, R.D. \& Saunders, D.S. (1991a) A coupled oscillator feedback system as a model for the photoperiodic clock in insects and mites. I. The basic control system as a model for circadian rhythms. Journal of Theoretical Biology, 152, 287-298.

Vaz Nunes, M., Saunders, D.S. \& Lewis, R.D. (1991b) A coupled oscillator feedback system as a model for the photoperiodic clock in insects and mites. II. Simulation of photoperiodic responses. Journal of Theoretical Biology, 152, 299-317.

Vaz Nunes, M. \& Veerman, A. (1982) Photoperiodic time measurement in the spider mite Tetranychus urticae: a novel concept. Journal of Insect Physiology, 28, 1041-1053.

Vaz Nunes, M. \& Veerman, A. (1986) A 'dusk' oscillator affects photoperiodic induction of diapause in the spider mite, Tetranychus urticae. Journal of Insect Physiology, 32, 605-614.

Veerman, A. (1977) Aspects of the induction of diapause in a laboratory strain of the mite Tetranychus urticae. Journal of Insect Physiology, 23, 703-711.

Veerman, A. (1985) Diapause. Spider Mites: their Biology, Natural 
Enemies and Control, Vol. 1A (ed. by W. Helle and M. W. Sabelis), pp. 279-319. Elsevier, Amsterdam.

Zaslavski, V.A. (1972) Two-step photoperiodic reactions as a basis for elaborating a model of the photoperiodic control of development in arthropods. Entomologicheskoe Obozrenie, 51, 217-239 (in Russian).
Zaslavski, V.A. (1988) Insect Development: Photoperiod and Temperature Control. Springer-Verlag, Berlin.

Accepted 21 August 1997 